\title{
Revision of the 'missed pill' rules
}

\author{
Diana Mansour
}

Clinical Director, Sexual Health Services, Newcastle Hospitals Community Health, New Croft Centre, Newcastle upon Tyne, UK

\section{Correspondence to}

Dr Diana Mansour, Sexual Health Services, Newcastle Hospitals Community Health, New Croft Centre, Market Street (East), Newcastle upon Tyne NE1 6ND, UK;

diana.mansour@

newcastle-pct.nhs.uk

Received 16 May 2011 Accepted 18 May 2011 Published Online First 29 May 2011
In 2005, the Clinical Effectiveness Unit (CEU) of the then Faculty of Family Planning and Reproductive Health Care adopted the World Health Organization (WHO) 'missed pills' guidance (Figure 1). ${ }^{1}$ Many clinicians criticised this change $e^{2-5}$ as these new rules appeared to be complex and caused confusion at the grass roots level..$^{6-8}$ There were also concerns that liberalising the 'missed pills' guidance (Box 1) $)^{9}$ would lead to additional unplanned pregnancies among pill-takers and did not support safer sex messages or the importance of correct and consistent pill-taking. ${ }^{235}$

Unfortunately the 2005 changes appeared to have been based on old papers since superseded. ${ }^{10-16}$ Even at that time there was evidence contradicting a relaxing of the rules. ${ }^{17-19}$ The CEU admitted they did not consider recently published evidence from 2003 and 2004, ${ }^{10}$ which was worrying as Pierson et al. ${ }^{19}$ demonstrated presumed ovulation in 13-19\% of 30-35 $\mu \mathrm{g}$ triphasic pill-users following a 3 -day dosing error thereby extending the pill-free interval.

Since then further evidence has been published suggesting that hormone-free intervals of 7 or more days can result in breakthrough ovulations and a significant increase in pill failure. ${ }^{20-22}$ One of the arguments posed suggested that even though studies reported higher ovulation rates, failure had not been linked with the 'pill-free' interval ${ }^{10}$ and these women did not become pregnant. However, it should be pointed out that women taking part in these studies used abstinence or barrier methods when pills were missed. Studies exploring ovarian follicular activity when extending the hormone-free interval include small numbers of women and are not powered to detect wide individual variation..$^{23}$ Authors of a systematic review in 2006 acknowledged that these studies also gave varied definitions of 'ovulation' and this inconsistency questions their methodology. ${ }^{23}$ Accurate detection of ovulation requires frequent and detailed endocrine and ultrasonic evaluation.
The 'missed pill' guidance in combined hormonal contraceptives' Summary of Product Characteristics leaflets is overcautious, particularly if pills are missed mid-packet (Box 1). ${ }^{9}$ In 2010, the UK's Medicines and Healthcare products Regulatory Agency (MHRA) recognised that there was a need to simplify these rules. The MHRA organised a meeting with representatives from a number of key UK organisations including the Faculty of Sexual and Reproductive Healthcare (FSRH), the FPA (Family Planning Association) and the pharmaceutical industry. The aim was to produce standardised guidance on the starting of combined hormonal contraceptives and on 'missed pills', emphasising the need for regular pill-taking and not 'missing pills' around the pill-free interval.

The MRHA '24-hour missed pill advice' (Box 2) is clear. ${ }^{24}$ No action needs to be taken until 24 hours or more has elapsed from the usual 'pill-taking' time. If this occurs, anywhere in the packet, the forgotten pill needs to be taken and the next pill when it is due - this may mean taking two pills in 1 day. No additional contraception is required.

If two or more pills are forgotten (more than 48 hours late) only the last 'forgotten' pill is taken and the next pill taken at the usual time - this may mean taking two pills in 1 day. Additional contraception is needed for the next 7 days. If there are fewer than seven pills left in the pack, the pack should be finished and a new pack started the next day missing out the break.

The 'emergency contraception (EC)' advice, however, is confusing. The MHRA suggest that only women "who have unprotected sex in the previous 7 days and have missed two or more pills in the first week of their pack" should seek advice about EC. What about those who have repeated unprotected sex from the start of the hormone-free interval? They could still receive EC. Improved wording would read that "women who have unprotected sex during the hormone-free interval or in the first week of pill taking 


$\begin{gathered}\text { If ONE or TWO } \\ \text { 30-35 } \mu \text { g ethinylestradiol } \\ \text { pills have been missed } \\ \text { at any time } \\ \text { OR }\end{gathered}$
ONE $20 \mu$ g ethinylestradiol
pill is missed

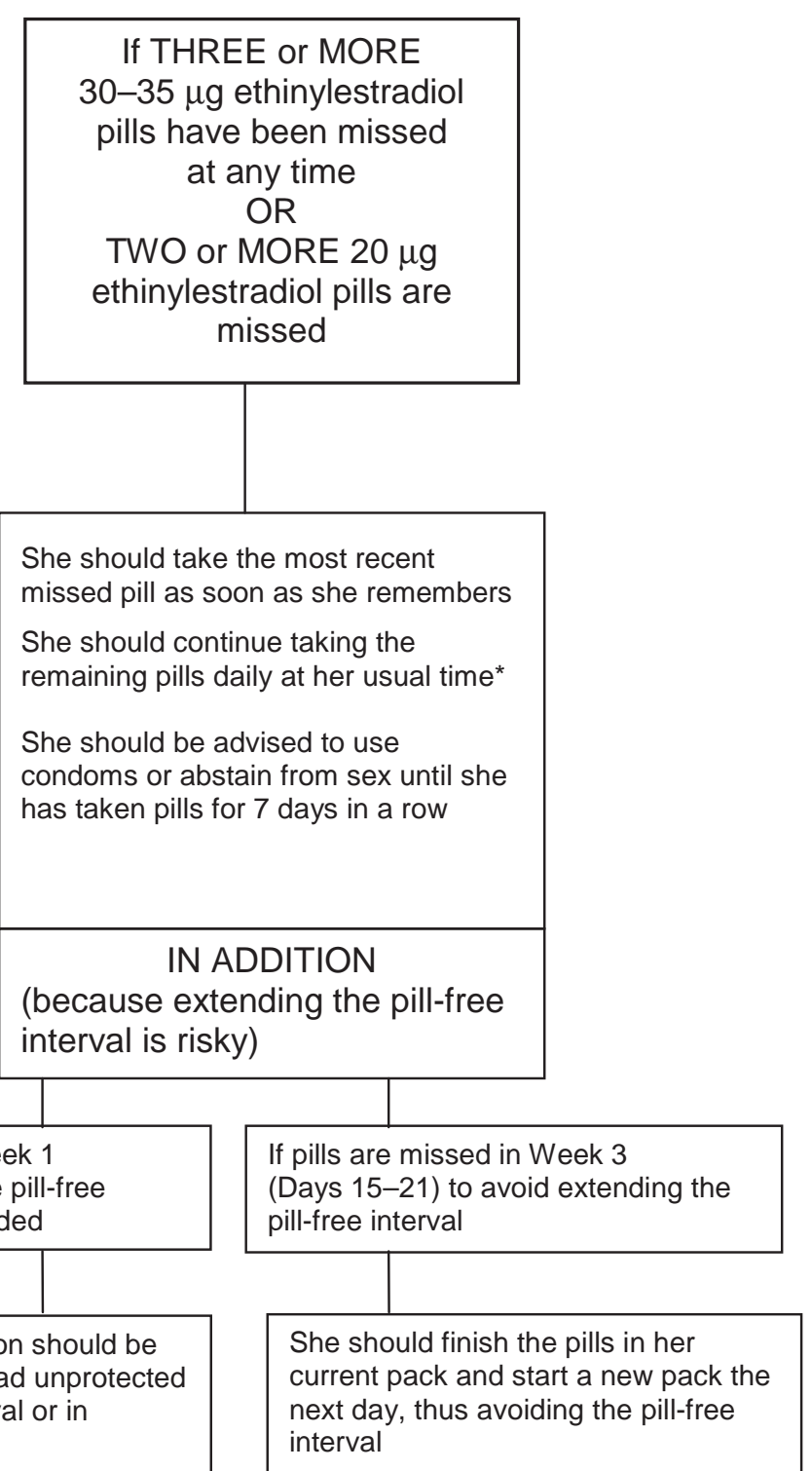

*Depending on when she remembers her missed pill she may take two pills on the same day, one when she remembers and the other at the regular time or both at the same time

For everyday regimes, if a woman misses any inactive pills she should discard the missed inactive pills and then continue taking pills daily, one each day

Figure 1 Advice from 2005 for women missing combined oral contraceptives (30-35 $\mu \mathrm{g}$ and $20 \mu \mathrm{g}$ ethinylestradiol formulations). ${ }^{1}$

\section{Box 1 'Missed pill' rules in the Summary of Product Characteristics ${ }^{9}$}

If the forgotten tablet is taken within 12 hours, no further precautions are necessary, further tablets should be taken at the usual time.

If one or more tablets are forgotten for more than 12 hours, contraceptive protection will be reduced. The patient should take the last forgotten tablet, even if this means taking two tablets in 1 day, and then continue to take tablets at the normal time. Additional contraceptive precautions should be taken for the next 7 days, and the patient should follow 'the 7-day rule'.

AND have missed two or more pills in that first week should seek advice about emergency contraception”.
True pill failures still occur and recent data suggest that a standard 7-day hormone-free break is too long for a small number of women. ${ }^{22} 25$ Six years after the publication of the WHO 'missed pill' guidance ${ }^{26}$ and CEU adoption of these rules a seminal paper has been published that clearly demonstrates the importance of the hormone-free interval for contraceptive efficacy. The International Active Surveillance of Women Taking Oral Contraceptives study in the USA followed 52218 women prospectively in a controlled, non-interventional manner. ${ }^{20}$ The aim was to analyse contraceptive failure in those taking oral contraceptives. Total oral contraceptive exposure was 73269 woman-years and a total 
Starting the pill.

You can start the pill any time in your menstrual cycle if you are sure you are not pregnant.

If you start the pill on the first day of your period you will be protected from pregnancy immediately.

- You can also start the pill up to, and including, the fifth day of your period and you will be protected from pregnancy immediately.

- If you start the pill at any other time in your menstrual cycle you will need to use additional contraception, such as condoms, for the first 7 days of pill taking

If you forget to take a pill or start a pack late

- Missing pills or starting the pack late may make your pill less effective. The chance of pregnancy after missing pills depends on when pills are missed and how many pills are missed. A pill is late when you have forgotten to take it at the usual time. A pill has been missed when it is more than 24 hours since the time you should have taken it.

- If you miss one pill anywhere in your pack or start the new pack 1 day late, you will still have contraceptive cover. However, missing two or more pills or starting the pack two or more days late (more than 48 hours late) may affect your contraceptive cover. As soon as you realise you have missed any pills, take the last pill you missed immediately. In particular, during the 7-day pill-free break your ovaries are not getting any effects from the pill. If you make this pill-free break longer by forgetting two or more pills, your ovaries might release an egg and there is a real risk of becoming pregnant.

- Follow the advice below. If you are not sure what to do, continue to take your pill and use additional contraception, such as condoms, and seek advice as soon as possible.

If you have missed one pill, anywhere in the pack:

- Take the last pill you missed now even if it means taking two pills in 1 day

- Continue taking the rest of the pack as usual

No additional contraception needed

- Take your 7-day break as normal.

If you have missed two or more pills (i.e. more than $\mathbf{4 8}$ hours late), anywhere in the pack:

Take the last pill you missed now even if it means taking two pills in 1 day

Leave any earlier missed pills

- Continue taking the rest of the pack as usual and use an extra method of contraception for the next 7 days

- You may need emergency contraception - see below

You may need to start the next pack of pills without a break - see below.

Emergency contraception

If you have had unprotected sex in the previous 7 days and you have missed two or more pills (i.e. more than 48 hours late) in the first week of a pack, you may need emergency contraception. Get advice from your contraception clinic, family doctor, or a pharmacist about this.

Starting the next pack after missing two or more pills (more than $\mathbf{4 8}$ hours late)

If seven or more pills are left in the pack after the last missed pill:

- Finish the pack

- Have the usual 7-day break

If less than seven pills are left in the pack after the missed pill:

Finish the pack and begin a new one the next day (this means missing out the break).

of 1634 unintended pregnancies occurred. On closer examination, only 229 (14\%) of these pregnancies arose in women who reported that they had taken their pills as directed. In answer to a direct query, the study authors have also reported that 'non-perfect' use was most frequent among adolescents. ${ }^{27}$ When studying women of all age groups, those taking a 24-day regimen containing a progestogen with a long half-life were less likely to have an unplanned pregnancy compared with those taking a conventional 21-day regimen. The adjusted hazard ratio was 0.7 (95\% CI 0.6-0.8). Importantly, this reduction of contraceptive failure was even more pronounced in adolescents. ${ }^{27}$ This 'real life' study of pill-users demonstrates the dangers of the hormone-free interval and points the way to further research into more flexible pill regimens where hormone-free intervals are decreased and overall efficacy improved.

Competing interests The author has received honoraria for lecturing, expenses for attending scientific conferences and research grants from a number of pharmaceutical companies including Bayer Schering Pharma, Schering-Plough Limited and Merck Sharp \& Dohme Limited (MSD).

Provenance and peer review Commissioned; internally peer reviewed.

\section{References}

1 Faculty of Family Planning and Reproductive Health Care Clinical Effectiveness Unit. Faculty statement from the CEU on a new publication: WHO Selected Practice Recommendations for Contraceptive Use Update. Missed pills: new recommendations. J Fam Plann Reprod Health Care 2005;31:153-155.

2 Mansour D, Fraser IS. Missed contraceptive pills and the critical pill-free interval. Lancet 2005;365:1670-1671.

3 Guillebaud J. Faculty statement from the CEU and fpa 'Your Guide to the Combined Pill' leaflet, April 2005, based on the WHO's 2004 Guidance re advice for missed COCs [Letter]. J Fam Plann Reprod Health Care 2005;31:252.

4 Hollingworth BA, Marfleet C. CEU statement on missed pills [Letter]. J Fam Plann Reprod Health Care 2005;31:253.

5 Killick SR. When is a pill missed? [Letter]. J Fam Plann Reprod Health Care 2005;31:254.

6 Smith D. Missed pills [Letter]. J Fam Plann Reprod Health Care 2005;31:253.

7 van der Westhuizen M, Hall D. Are affluent, well-educated, careerorientated women knowledgeable users of the oral contraceptive pill? J Fam Plann Reprod Health Care 2005;31:307-309.

8 Willis C, Whitwell I. Missed pill guidelines [Letter]. J Fam Plann Reprod Health Care 2005;31:336.

9 Merck, Sharp and Dohme. Marvelon: Summary of Product Characteristics. 2009. http://www.medicines.org.uk/emc/ medicine/5383/SPC/ [accessed 22 January 2011].

10 Penney G, Brechin S, Glasier A, et al. Missed contraceptive pill recommendations. Lancet 2005;366:1264. 
11 Creinin MD, Lippman JS, Eder SE, et al. The effect of extending the pill-free interval on follicular activity: triphasic norgestimate/35 micro g ethinyl estradiol versus monophasic levonorgestrel/20 micro g ethinyl estradiol. Contraception 2002;66:147-152.

12 Elomaa K, Rolland R, Brosens I, et al. Omitting the first oral contraceptive pills of the cycle does not automatically lead to ovulation. Am J Obstet Gynecol 1998;179:41-46.

13 Hamilton CJ, Hoogland HJ. Longitudinal ultrasonographic study of the ovarian suppressive activity of a low-dose triphasic oral contraceptive during correct and incorrect pill intake. Am J Obstet Gynecol 1989;161:1159-1162.

14 Hedon B, Cristol P, Plauchut A, et al. Ovarian consequences of the transient interruption of combined oral contraceptives. Int J Fertil 1992;37:270-276.

15 Killick SR, Bancroft K, Oelbaum S, et al. Extending the duration of the pill-free interval during combined oral contraception. Adv Contracept 1990;6:33-40.

16 Smith SK, Kirkman RJ, Arce BB, et al. The effect of deliberate omission of Trinordiol or Microgynon on the hypothalamopituitary-ovarian axis. Contraception 1986;34:513-522.

17 Elomaa K, Lähteenmäki P. Ovulatory potential of preovulatory sized follicles during oral contraceptive treatment. Contraception 1999;60:275-279.

18 Baerwald AR, Olatunbosun OA, Pierson RA. Ovarian follicular development is initiated during the hormone-free interval of oral contraceptive use. Contraception 2004;70:371-377.

19 Pierson RA, Archer DF, Moreau M, et al. Ortho Evra/Evra versus oral contraceptives: follicular development and ovulation in normal cycles and after an intentional dosing error. Fertil Steril 2003;80:34-42.

20 Dinger J, Minh TD, Buttmann N, et al. Effectiveness of oral contraceptive pills in a large U.S. cohort comparing progestogen and regimen. Obstet Gynecol 2011;117:33-40.

21 Birtch RL, Olatunbosun OA, Pierson RA. Ovarian follicular dynamics during conventional vs. continuous oral contraceptive use. Contraception 2006;73:235-243.

22 Klipping C, Duijkers I, Trummer D, et al. Suppression of ovarian activity with a drospirenone-containing oral contraceptive in a 24/4 regimen. Contraception 2008;78:16-25.

23 Curtis KM, Chrisman CE, Mohllajee AP, et al. Effective use of hormonal contraceptives: part I: combined oral contraceptive pills. Contraception 2006;73:115-124.

24 Medicines and Healthcare products Regulatory Authority (MHRA). MHRA UK Public Assessment Report. Combined Oral Contraceptives (The Pill): When to Start Taking The Pill, and Missed Pill Advice. May 2011. http://www.mhra.gov.uk/Safetyinformation/ Generalsafetyinformationandadvice/Product-specificinformation andadvice/Product-specificinformationandadvice-G-L/ Hormonalcontraceptives/index.htm [accessed 13 May 2011].

25 Trussell J. Understanding contraceptive failure. Best Pract Res Clin Obstet Gynaecol 2009;23:199-209.

26 World Health Organization. Selected Practice Recommendations for Contraceptive Use (2nd edn). 2004. http://whqlibdoc.who.int/ publications/2004/9241562846.pdf [accessed 30 January 2011].

27 Dinger J. Comparative effectiveness of combined oral contraceptives in adolescents [Letter]. J Fam Plann Reprod Health Care 2011;37:118. 